\title{
Kinetic Analysis of Four-link Gantry Crane Hoisting System
}

\author{
Si Li FAN ${ }^{1}$,Yu Feng $\mathrm{SHU}^{1}$, Hai Ying ZHANG $^{1}$, Shuo OUYANG \\ ${ }^{1}$ DongGuan Polytechnic, DongGuan523808, China.
}

\begin{abstract}
This paper establishes a flexible dynamics model of MQ2533 portal crane boom system. In the premise of ignoring control system, this paper analysis the mechanical dynamics of boom hoisting system. Simulation results show that: Dynamics response of the hoisting boom system have great fluctuation when excluding the control effects, this paper provide a theoretical basis for crane hoisting system to optimize control strategies, which committed to improve their performance and ensure safety, reliability and economy.
\end{abstract}

Keywords: Crane, Force, Displacement, Hoisting system.

\section{Introduction}

Gantry crane is a large construction machinery, mainly used for port, berth, open stockyards and outfitting site. It has good transport, big depth of spreader decentralization, better adapt to the temporary work and so on. we should full considerate its strength, rigidity and safety when design, but also to reduce the supplies and cost savings. Boom system is an actuator of portal crane, it is the design basis of electrical systems and other subsidiary organs. In order to simplify the calculation under the normal circumstances, we consider the mechanical components as rigid body ${ }^{[1]}$, But when we need a high precision calculation or study the stress magnitude, distribution and deformation within the body, you need to regard it as a flexible member. Precise kinetic analysis can make sure the gantry crane safety and performance, minimize its weight 、 reduce noise and prevent the shock loads. Thus, kinetic analysis of four-link gantry crane hoisting system is particularly necessary ${ }^{[2-3]}$.

ADAMS has unparalleled advantages in dynamics analysis of rigid body than the other software, but very weak in flexible mesh unit and other processing functions. Flex module provides bi-directional data exchange interface with other finite element software(such as ANSYS, NASTRAN etc). We can import the modal neutral file(*.mnf) of other finite element software into ADAMS through interface ${ }^{[4]}$.

The main component of MQ2533 portal crane boom system comprises of nose, large rod, small rod, girder and etc. In order to understand its mechanical properties of displacement response of key nodes, stress, deflection, vibration frequency, we need to treat it as a flexible body; For the pulley, reel, small rod, balance beam and hoist and other ancillary components, we only need to know their motion parameters such as size, quality and moment inertia, thus regard them as rigid bodies $^{[5-6]}$. MQ2533 portal crane is shown in Figure 1. 


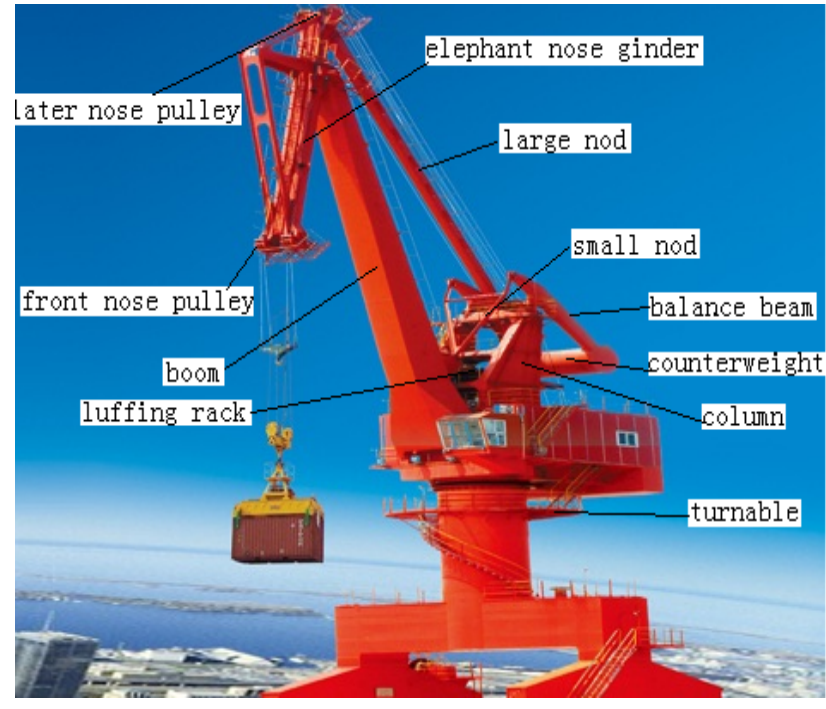

Figure 1. Four-link portal crane of MQ2533

This paper establish the flexible model through bushing which connected wire rope and many small cylindrical. The hinged position with revolute appeared in vice establishment of constraints. We regard a rigid sphere weighed $25 \mathrm{e} 3 \mathrm{Kg}$ as loads, constrainting through the spherical jiont. We build a cuboid as ground wich force constrainted with the loads in order to simulate the lifting process. Rigid and flexible coupling model of boom system is shown in Figure 2.

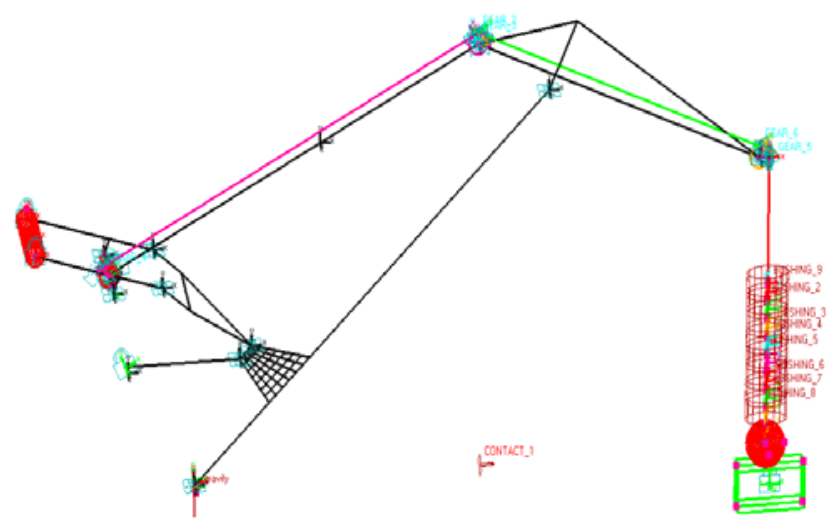

Figure 2. Rigid and flexible coupling model of boom system

\section{Parameters Calculation}

Table 1 lists the device types of power and drive system of MQ2533 gantry crane ${ }^{[7]}$.
Table 1. Device types of power and drive system

\begin{tabular}{ccc}
\hline Category & Model & Number \\
\hline Motor & YZPF315L-8 & 2 \\
Reducer & M3PSF80-40-124 & 2 \\
Arrester & YWZ5-500/200 & 2 \\
Nominal diameter & 0.92 & 2 \\
of drum (m) & & \\
Wire rope & 26NAT18X7SW+FC1670ZS/ & 4 \\
& SZ & \\
\hline
\end{tabular}

Seen from Tab.1 above, driving motor and transmission system both have two sets. motor is variable for frequencies and reducer magnification is 40 , Then driving torque of drum to wire rope is $80 \eta$ times of the single $\operatorname{motor}(\eta$ is equal to 0.9 , which is the total efficiency of motor to drum ${ }^{[8]}$ ).

Nameplate data of the motor shows that ratio of starting torque and rated torque $(1700 \mathrm{~N} / \mathrm{m})$ is $\lambda_{0}=1.8$, ratio of the biggest torque and rated torque is $\lambda=3$, The diving torque equation are as follows:

$\left\{\begin{array}{l}T=112531 \omega+203760, \omega \leq 1.8107 \\ T=-1.03 E 10+1.06 E 10 \omega-2.73 E 9 \omega^{2}, \text { other }\end{array}\right.$

Drive system parameters are shown in Table 2:

Table 2. Drive system parameters

\begin{tabular}{|l|l|}
\hline \multicolumn{1}{|c|}{ Denomination } & Value \\
\hline Equivalent inertia ofdrum $J_{r}\left(\mathrm{Kg} \cdot \mathrm{m}^{2}\right)$ & $7.168 \mathrm{e} 4$ \\
\hline Initial length of wirerope $l_{0}(\mathrm{~m})$ & 60 \\
\hline Rigidity coefficient ofwire rope $E_{c}(\mathrm{~N} / \mathrm{m})$ & $9.12 \mathrm{e} 6$ \\
\hline $\begin{array}{l}\text { Damping coefficient ofwire rope } \\
C_{c}\left(\mathrm{~N} / \mathrm{m} \cdot \mathrm{s}^{-1}\right)\end{array}$ & $1.9 \mathrm{e} 4$ \\
\hline
\end{tabular}

\section{Simulation Results}

We set parameters as follws in ADAMS: starting torque of equivalent drum is 1.8 times of the rated torque, which is equal to 203760 N.m, then we can calculate the driving torque of equivalent drum acording to the equivalent above, and the terminal simulation time is $5 \mathrm{~s}^{[9]}$.

Figure3 to Figure8 show the front and rear displacement responses and stress changes of the elephant nose girder, load 
torque characteristics of the conversion to motor is shown in Fig.ure9, Fig.ure10 depicts the tension value variation of wire rope along with time.

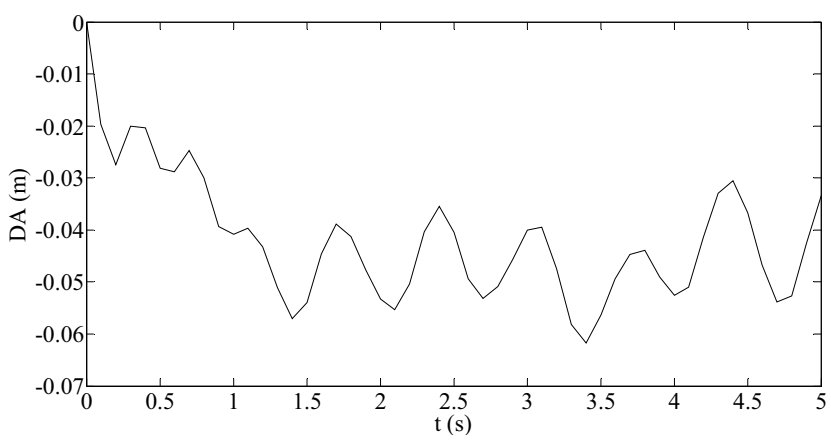

Figure 3. The front displacement response

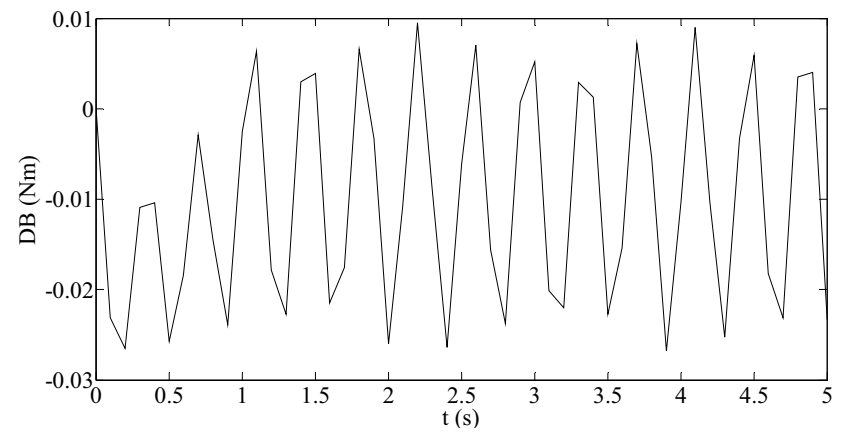

Figure 4. The rear displacement response

Seen from Fig.3, the front displacement of girder gradually decreases to $-0.055 \mathrm{~m}$ from static equilibrium position within the first 1.5 seconds, For the 3.5 seconds behind, the displacement changes in vicinity of $-0.0466 \mathrm{~m}$, The biggest amplitude is $-0.03 \mathrm{~m}$, and relative rate of change is $35.6 \%$, which explains a large fluctuation.

Fig.4 shows the rear displacement of girder fluctuation both sides of the equilibrium position which is equal to $-0.01 \mathrm{~m}$, and the biggest displacement exceed the static equilibrium position before lifting. Comparate Fig. 3 and Fig.4 after lifting, we can see the front equilibrium value is 5.5 times the rear one, so the front stiffness of girder is worse than the rear.

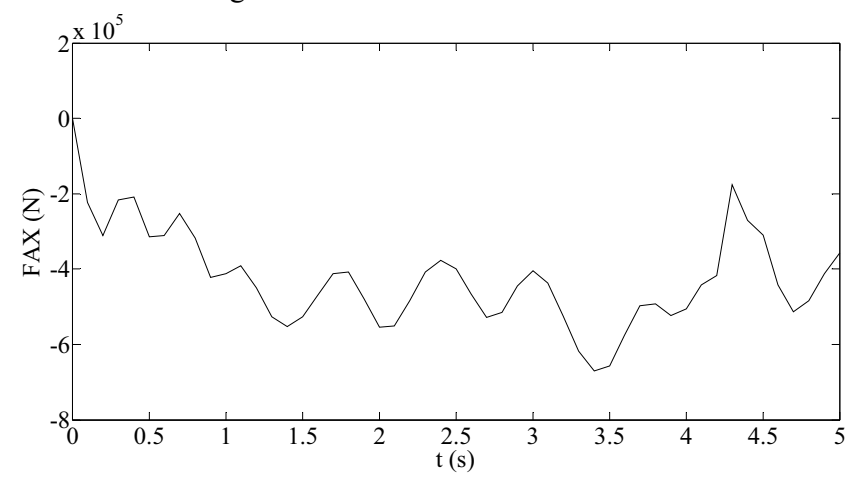

Figure 5. The front horizontal force

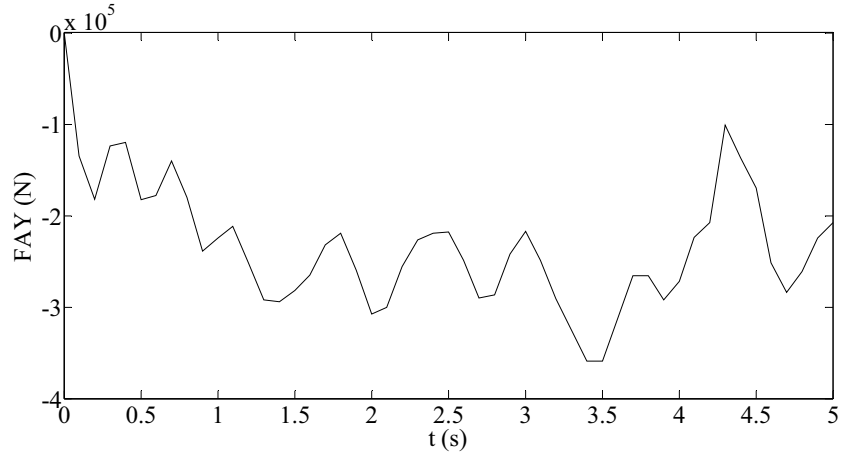

Figure 6. The front vertical force

Fig.5 shows that the front vertical force of elephant nose girder increase from 0 to $5 \times 10^{5} \mathrm{~N}$ within the first 1.5 seconds, then fluctuate in the vicinity of $4.68 \mathrm{e}^{5} \mathrm{~N}$. The biggest amplitude is $2.03 \mathrm{e}^{5} \mathrm{~N}$ in the $3.5 \mathrm{~s}$ later, and relative change rate is $56.6 \%$.

Seen from Fig.6, the front vertical force of elephant nose girder gradually increase to $2.82 \mathrm{e}^{5} \mathrm{~N}$, then fluctuate in the vicinity of $2.54 \mathrm{e}^{5} \mathrm{~N}$, which lies in the static equilibrium position. The biggest amplitude is $1.53 \mathrm{e}^{5} \mathrm{~N}$ in the $3.5 \mathrm{~s}$ later, and relative change rate is $39.8 \%$, indicating the vertical force has a big fluctuation.

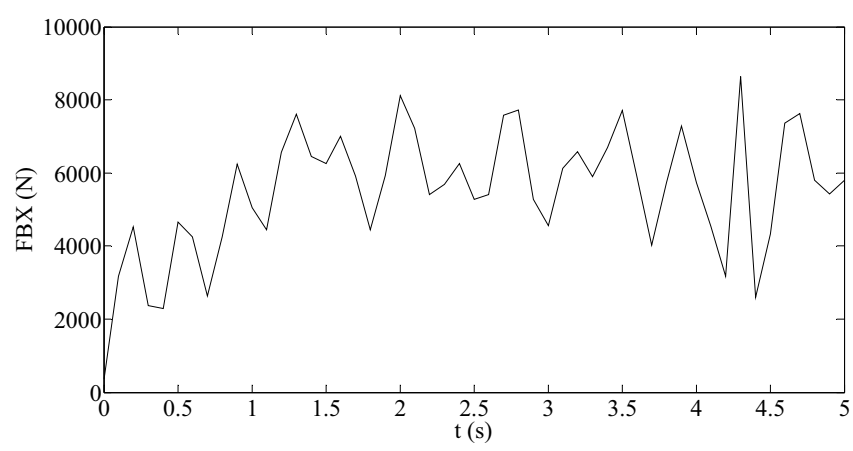

Figure 7. The rear horizontal force

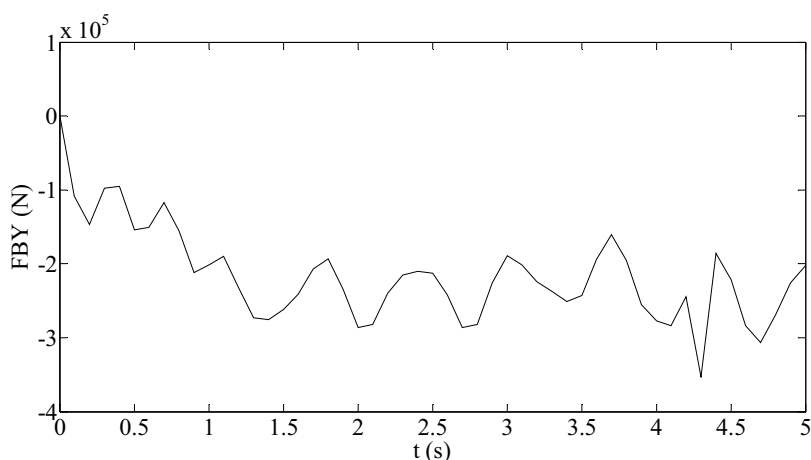

Figure 8 . The rear vertical force 
Seen from Figure 7 and Figure 8, the rear horizontal force has a significant fluctuation in the both sides of 5974 N. Nonetheless, it reduces two orders of magnitude than the load, but the magnitude vertical force remains the same order with load. The biggest amplitude of vertical force is $1.1343 \mathrm{e}^{5} \mathrm{~N}$ in $3.5 \mathrm{~s}$ later, and relative change rate is $52.7 \%$ with respect to the average force $2.396 \mathrm{e} 5 \mathrm{~N}$.

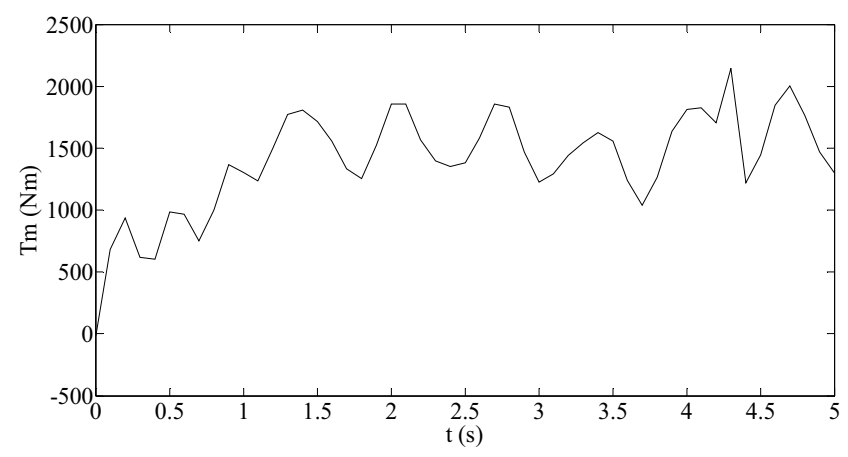

Figure 9. Load torque of motor

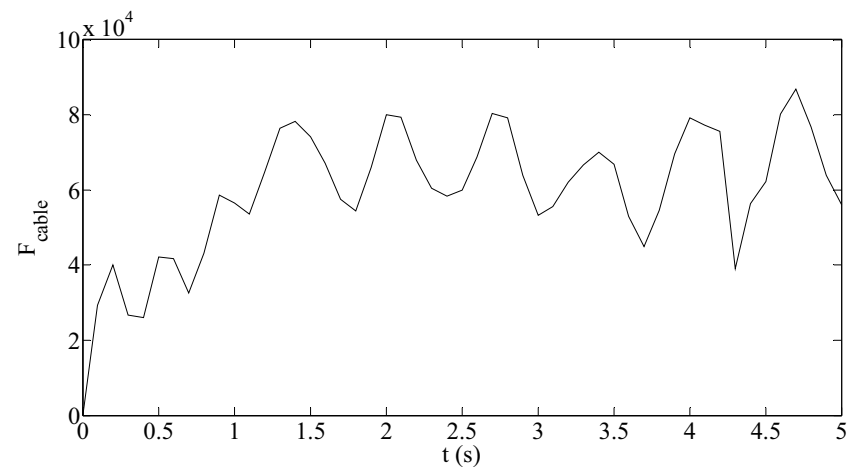

Figure 10. Rope force

We can only get the load torque of equivalent reel in simulation results, but can not directly obtain the input load torque of drive motor. The magnification formula: $T_{\mathrm{m}}=T_{\mathrm{r}} / 80 /$, ( is the overall efficiency of motor to drum).

According to the simulation shown in Fig.9, load torque of motor increase to $1903 \mathrm{~N} \cdot \mathrm{m}$ erratically within the first $1.5 \mathrm{~s}$. The average value is $1727 \mathrm{~N} . \mathrm{m}$ after $1.5 \mathrm{~s}$, the biggest change is $655 \mathrm{~N} \cdot \mathrm{m}$, and relative change rate is $62.1 \%$ with respect to the average one.

MQ2533 crane has four ropes, according to the principle of total stiffness constant in ADAMS model, simplifing the four ropes as one. This paper regard a quarter of the measured force as one rope suffered.
Fig.10 demonstrate that rope force increase to $74200 \mathrm{~N}$ within the first $1.5 \mathrm{~s}$, and it has a large fluctuation at the equilibrium position which is equal to $65756 \mathrm{~N}$, the biggest change is $26656 \mathrm{~N}$ after $1.5 \mathrm{~s}$, accounting for $59.5 \%$ of the average one.

\section{Summary}

First of all, this paper uniformly convert the powertrain inertia into drum in accordance with the reasonable assumption, including the flexible vibration characteristics of wire rope and combining the mechanical properties of driving motor and Newton's law. Based on these, it determine the input torque equation of flexible dynamic model of boom system. Furthermore, establishing the flexible dynamics model of the boom system.

This paper analysis the mechanical dynamics of MQ2533 portal crane hoisting system ignoring the role of system control. Simulation results show that: Dynamics response of boom hoisting system has a great fluctuatation when excluding the effect of control system. Next, we will be able to optimize the hoisting system of portal crane considering the frequency vector control mode and improve its control strategy and performance, which can ensure its safety, reliability and economy.

\section{References}

1.Imanishi Etsujiro, Nanjo Takao, Kobayashi Takahiro . Dynamic simulation of wire rope with contact $[\mathrm{J}]$. 2009, 23(4): 1083-1088.

2. BS EN 13001-2: 2004+A3, Crane saftey General desigen, Part 2: Load actions[S]. 2009.

3. Liming Li, Practical guide of finite element analysis, Tsinghua University Press. beijing, 2005.1, pp. 111-116.

4.Shuoouyang. Research on Dynamic Characteristics of For-bar Linkage Portal Crane Hoisting System[D]. Changsha, Central South University, 2013.5.

5.Zhong Liu. Dynamics Simulation Study of Hoisting Mechanism of Double-girder Overhead Travelling Crane[D]. Changsha, Central South University of Forestry and Technology, 2014.5. 
6. Information on http://www.image.baidu.com.

7.Ghigliazza R M, Holmes P. On the dynamics of cranes, or spherical pendulum with moving supports[J]. International journal of non-linear mechanics. 2002,37(7);1211-1221.

8.Ellermann K, Kreuzer E. Nonlinear dynamics in the motion of floating cranes [J]. Multibody system dynamics. 2003, 9(4): 377-387.

9.QiuXiuyun, Zhao Tao etc.. Analysis on damping ratio of single factor and simulation of many factors optimize combination with suspension girder in $\operatorname{ppr}[\mathrm{J}]$. Journal of Xinjiang agricultural university, 2003,35(6): 2-3. 